\title{
O CONTROLE DA REPRODUÇÃO ESTÁ NO CORAÇÃO DA ORGANIZAÇÃO SÓCIO-POLÍTICA. A DISCUSSÃO SOBRE A DESCRIMINALIZAÇÃO DA PRÁTICA DA INTERRUPÇÁO DA GRAVIDEZ VOLUNTÁRIA NO BRASIL
}

\author{
THE CONTROL OF REPRODUCTION IS AT THE HEART ON THE SOCIOPOLITICAL \\ ORGANIZATION DISCUSSION ON THE DECRIMINALIZATION OF THE PRACTICE OF \\ INTERRUPTION OF VOLUNTARY PREGNANCY IN BRAZIL
}

Viviana Mendes Ribeiro

Doutoranda do Departamento de Direito do Programa de Pós-Graduação em Teoria do Estado e Direito Constitucional da PUC-Rio Professora e Cofundadora do IPIA - Comunidade de Pensamento vivianamribeiro@gmail.com

\section{RESUMO}

Este artigo propóe um breve histórico político sobre a perda do controle da reprodução pelas mulheres, acontecimento histórico que, como será verificado, ocupa o centro da organização política do Estado Moderno e do capitalismo, conforme o pensamento da feminista marxista Silvia Federici. Consequentemente, a conquista do direito à interrupção da gestação pelas mulheres não trata, apenas, de um direito de liberdade individual delas, sintetizado pelas palavras de ordem de certa vertente do movimento feminista "meu corpo, minhas regras". Trata, principalmente, de uma das questóes que ocupa o coração da política; o fato de que, no Brasil, a questão ainda encontre tantas dificuldades para avançar, apesar do custo social da realização de abortos inseguros - automutilaçóes, lesões graves, óbitos e criminalizaçóes, especialmente das mulheres pobres - ser superior aos benefícios que se pretende alcançar com a condenação legal da conduta, denota o enraizamento profundo, na estrutura social brasileira, do patriarcalismo autoritário, no qual Estado e capitalismo cooperam entrelaçando e mantendo as desigualdades sociais, de gênero e de raça.

Palavras-chave: Controle. Reprodução. Mulheres. Capitalismo. Política.

\begin{abstract}
This article proposes a brief political history about the loss of control over reproduction by women, a historical event that, as will be seen, occupies the center of the political organization of the Modern State and capitalism, according to the thought of the Marxist feminist Silvia Federici. Therefore, the conquest of the right to termination of pregnancy by women is not just a women's right to individual freedom, synthesized by the slogans of a certain aspect of the feminist movement as "my body, my rules". However, this is one of the issues that occupy the heart of politics. The fact that, in Brazil, the issue still faces so many
\end{abstract}


difficulties to move forward, although the social cost of performing unsafe abortions self-harm, serious injuries, deaths and criminalization, especially of poor women - is greater than the benefits that are intended to be achieved with the criminalization of this conduct, it denotes the deep rooting, in the Brazilian social structure, of authoritarian patriarchalism, in which State and capitalism cooperate intertwining and maintaining social, gender and race inequalities.

Keywords: Control. Reproduction. Women. Capitalism. Politics.

Data de submissão: 14/07/2020.

Data de aceitação: 19/02/2021

\section{SUMÁRIO}

INTRODUÇÃO: O CONTROLE DA REPRODUÇÃO ESTÁ NO CORAÇÃO DA POLÍTICA - A MARCA DA HISTÓRIA 1. OS ARGUMENTOS JURÍDIÇOS DO HC 124.306 1.1 O caso concreto 1.2 Da violação aos direitos fundamentais das mulheres 1.3 Violação ao princípio da proporcionalidade 2. DEBATE SOBRE A DESCRIMINALIZAÇÃO DA INTERRUPÇÃO VOLUNTÁRIA DA GRAVIDEZ NO BRASIL AUDIÊNCIA PÚBLICA REALIZADA NA ADPF 4452.1 Estudo do Núcleo de Promoção e Defesa dos Direitos das Mulheres - Defensoria Pública Estadual de São Paulo CONSIDERAÇÕES FINAIS. REFERÊNCIAS.

\section{INTRODUÇÁO: O CONTROLE DA REPRODUÇÃO ESTÁ NO CORAÇÁO DA POLÍTICA - A MARCA DA HISTÓRIA}

Friedrich Engels em A origem da família, da propriedade privada e do Estado, publicado em 1884, baseado nas anotaçóes deixadas por Karl Marx sobre o Ancient Society $^{1}$, do antropólogo Lewis Morgan, associa a configuração da família em um modelo monogâmico-patrilinear ao surgimento da propriedade privada. Sociedades chamadas por Morgan de "selvagens" tinham como características, em linhas gerais: o nomadismo, relaçôes familiares definidas pelo vínculo do parentesco - e não o sanguíneo -, relaçôes não monogâmicas e a determinaçáo de filiaçáo reconhecida apenas pelo lado materno, ou seja, a descendência era estabelecida apenas pela linhagem matrilinear. Nessas sociedades, as mulheres ocupavam um lugar central e não eram hierarquicamente inferiorizadas em razão das atividades que desempenhavam. Todos contribuíam para o sustento da comunidade. Elas eram concebidas como semideusas, pois os homens desconheciam seu papel na reprodução humana².

1 MORGAN, L. H. La société archaïque, 1971.

2 MURARO, R. M. Prefácio. In: KRAEMER, H.; SPRENGER, J. O martelo das feiticeiras, 2017. 
Com o estabelecimento da agricultura, a domesticação de animais e a criação do gado, novas relaçóes sociais se estabeleceram em virtude do surgimento de estoque, da sofisticação dos utensílios e da geração de riquezas, assim, teria aparecido o problema: a quem pertence essas riquezas? O homem, enquanto responsável por procurar a alimentaçáo e deter as ferramentas de trabalho para tal tarefa, tornou-se proprietário dos instrumentos, enquanto à mulher pertencia os instrumentos domésticos. Consequentemente, o homem tornou-se proprietário do estoque de alimentaçáo, do gado e, mais adiante, dos escravos. Como a linhagem da descendência era apenas materna, não se conhecia a descendência paterna, e isso impossibilitava a transmissáo dessas propriedades para o descendente considerado.

À medida que as riquezas aumentavam, o homem fortalecia sua importância social e familiar superior e, com efeito, nasceu o desejo de tirar vantagem dessa posiçáo para que suas propriedades pudessem ser transmitidas a seus filhos considerados. Assim, de acordo com Morgan-Engels, as relaçóes familiares se alteram para o modelo monogâmico, com o objetivo de controlar a reprodução humana e, assim, a designação de descendência muda da linhagem matrilinear para a linhagem patrilinear. Conforme assevera Engels:

A derrubada do direito materno representou a derrota do sexo feminino no plano da história mundial. O homem assumiu o comando também da casa, a mulher foi degradada, escravizada, tornou-se escrava do desejo do homem e mero instrumento de procriaçáo ${ }^{3}$.

As conclusóes apresentadas por Engels em A origem da família, da propriedade privada e do Estado suscita, até hoje, diversos debates e divergências ${ }^{4}$, por diferentes vertentes antropológicas ${ }^{5}$ e filosóficas políticas ${ }^{6}$, divergências essas possibilitadas, inclusive, pelo desenvolvimento dos métodos antropológicos de análise; porém, há uma concordância entre as (os) pesquisadores quanto às características definidoras da estrutura social patriarcal: ela determina a descendência por meio da linhagem patrilinear e a organização da vida coletiva aparece como atividade predominantemente masculina.

A pensadora feminista marxista Silvia Federici, em seu livro Calibã e a bruxa, faz uma análise acerca da genealogia da formação dos Estados Modernos e dos processos de acumulação primitiva de capital que possibilitaram o surgimento do capitalismo, de acordo com o pensamento formulado por Marx, inserindo na análise da formação do capitalismo o fenômeno da caça às bruxas - perseguição, tortura e morte de milhares de mulheres, promovidas pelo Tribunal da Inquisição e pelo Estado, entre os séculos XV e XVII. Nesse

\footnotetext{
${ }^{3}$ ENGELS, F. A origem da família, da propriedade privada e do Estado, 2019, p. 60.

${ }^{4}$ Divergências sobre insuficiências do estudo, conclusóes sem premissas, origens da formação dos processos analisados e certas incongruências entre os manuscritos/versóes de Marx e as (re)ediçóes de Engels.

5 Ultrapassa os limites deste artigo apresentar as diferentes análises antropológicas que divergem das premissas e/ou as conclusōes do livro A origem da família, da propriedade privada e do Estado. Ver as obras: Antropologia estrutural; Cultura na prática; A sociedade contra o Estado; O gênero da dádiva: problemas com as mulheres e problemas com a sociedade na Melanésia; e A criaçáo do patriarcado: história da opressão das mulheres pelos homens.

${ }^{6}$ No âmbito da filosofia política, ver as obras: Mil platôs: capitalismo e esquizofrenia e Marx nas margens: nacionalismo, etnia e sociedades não ocidentais.
} 
estudo, a autora pretende responder as seguintes questóes: por que no momento de formação dos Estados Modernos e do surgimento do capitalismo se realizou um massacre de mulheres nunca visto antes na história? Qual a relação entre esse massacre de mulheres com o surgimento dos Estados Modernos e do capitalismo e quais foram as suas consequências? E a pergunta que se extrai das entrelinhas: qual é a relação, afinal, entre o Estado, o capitalismo e o patriarcado?

Federici apresenta, em linhas gerais, as seguintes teses para essas interrogaçóes: i) a expropriação das terras comunais e dos meios de produção, a escravização das populaçóes nativas das Américas e da população negra do continente africano, o desenvolvimento do mercantilismo e do colonialismo nas Américas com a extração e o roubo dos metais preciosos remetidos para a Europa, esses não foram os únicos processos integrantes da acumulação primitiva do capital e da força de trabalho, devendo ser incluído também os acontecimentos históricos da Inquisição e a caça às bruxas; ii) por meio da caça às bruxas, consolidou-se, na estruturação da sociedade moderna, a degradação social das mulheres e a legitimação social da violência contra elas, configurando-as como agentes sociais que devem ser temidos, odiados e exterminados; iii) tal estatuto social degradado institucionalizou e legitimou as práticas sociais de violência contra as mulheres, uma inovaçáo na história da sociedade patriarcal, a partir da disseminação e interiorização dos afetos de ódio e medo em relação às mulheres nas relaçóes sociais; iv) essa degradação operou um duplo efeito a favor do capitalismo: a sujeição das mulheres à reprodução da força de trabalho e da vida, e a divisão da unidade da classe trabalhadora em razão do gênero; v) a caça às bruxas promoveu a retirada violenta do controle da reprodução das mulheres, transformando a reprodução em assunto de Estado e centro da organização da política. Para fins deste artigo, interessa-nos analisar, neste momento ${ }^{7}$, apenas a última tese mencionada.

Até o século XIV, práticas de controle da reprodução - contracepção, interrupção da gravidez e infanticídio - eram realizadas pelas mulheres e tinham certa tolerância social, especialmente quando realizadas por mulheres pobres. Com a ocorrência da grande crise demográfica que dizimou $1 / 3$ da população europeia - em alguns lugares até $50 \%$ da população - pela fome, peste e guerras, foi produzida uma enorme crise de escassez da máo de obra e, com efeito, a classe camponesa da época foi fortalecida na luta e houve insurgências contra as arbitrariedades do sistema feudal. Foi nesse contexto histórico que o Tribunal da Inquisição intensificou as perseguiçóes, torturas e mortes - em nome do combate aos grupos heréticos - voltando-se, gradativamente, para as mulheres, de modo que, no início do século XV, a mulher acusada de bruxaria era o principal alvo de perseguição, e o crime de bruxaria era definido pelos inquisidores como a maneira pela qual os Demônios ${ }^{8}$ intervinham na humanidade, inserindo o mal e combatendo a ordem suprema de Deus. Essa intervenção dos Demônios se dava por meio de relaçóes sexuais e as mulheres eram entendidas como as mais

\footnotetext{
7 A proposta teórica apresentada por Silvia Federici em sua obra, não apenas em Calibã e a bruxa, é objeto de análise da pesquisa de doutorado, em desenvolvimento, da autora deste artigo. Para Federici, o acontecimento histórico da Inquisição foi indispensável para o advento do capitalismo, em razão da destruição do comum possível entre mulheres, acompanhado da expropriação da terra e da divisão da classe trabalhadora pelo gênero.

8 Este artigo reproduz a forma da gráfica do vocábulo Demônios conforme conservado na ediçáo brasileira do Martelo das feiticeiras, mencionada adiante.
} 
fracas por essência ${ }^{9}$ mental, espiritual, moral e fisicamente, maldosas por natureza; por isso, mais suscetíveis a cair nas armadilhas dos Demônios e arrastar os homens e a sociabilidade política com elas. Esta tipificaçáo do crime de bruxaria encobria, na verdade, a questão concreta que se almejava alcançar: retirar o controle da reprodução exercido pelas mulheres por meio de suas práticas e saberes compartilhados, subjugando-o ao controle do poder estatal, neste momento histórico exercido pela Igreja e, posteriormente, pelo Estado.

O crime de bruxaria era caracterizado pela realização de práticas de controle da reprodução. Também foi difundido amplamente que as mulheres, em comunhão com os Demônios, possuíam poderes de infertilizar os homens. A tipificação do delito de bruxaria é apresentada na Questão VI do Martelo das feiticeiras, manual da Inquisição, produzido pelos perseguidores Heinrich Kraemer e James Sprenger, em 1484, documento penal e processual penal orientador das práticas da Inquisição:

\section{QUESTÃO VI}

Sobre as bruxas que copulam com Demônios. Por que principalmente as mulheres se entregam às superstiçóes diabólicas.

Há também, a respeito das bruxas que copulam com Demônios, muitas dificuldades ao considerarem-se os métodos pelos quais a abominação é consumada. Da parte dos Demônios: primeiro, de qual dos elementos que compóem o corpo ele se utiliza; segundo, se o ato é sempre acompanhado da injeçáo do sêmen recebido de outro homem; terceiro, quanto ao momento e ao lugar, ou seja, se pratica $\mathrm{o}$ ato mais frequentemente em determinado momento do que em outro; quarto, se o ato não é visível aos que estão perto. Da parte das mulheres, cumpre indagar se apenas as que foram concebidas dessa forma obscena são frequentemente visitadas pelos Demônios, ou se o são apenas aquelas oferecidas aos Demônios pelas parteiras por ocasião de seu nascimento; e por fim, se o deleite com o ato venéreo é de algum tipo mais fraco. Não podemos responder a todas essas questóes por estarmos empenhados somente num estado geral. [...] Vamos nos deter por ora, no problema das mulheres; e, em primeiro lugar, tentaremos explicar por que essa perfídia é mais encontrada em pessoa do sexo frágil e não em homens. Nossa primeira indagação será de caráter geral - quanto às condiçôes gerais das mulheres; a segunda será particular - quanto ao tipo de mulher que se entrega à superstição e à bruxaria; e por fim a terceira, específica às parteiras, que superam todas as demais em perversidade.

[...] Qual o tipo de mulher que se entrega, mais que todas as outras, $\grave{a}$ superstição e à bruxaria

Cumpre dizer, conforme se demonstrou na questão precedente, que três parecem ser os vícios que exercem um domínio especial sobre as mulheres perversas, quais sejam: a infidelidade, a ambição e a luxúria. São estas, portanto, mais inclinadas que as outras à bruxaria,

${ }^{9}$ Ou seja, por natureza constitutiva biológica das mulheres. 
por mais se entregarem a tais vícios. Como desses três vícios predomina o último, por serem as mulheres insaciáveis etc., conclui-se que, dentre as mulheres ambiciosas, as mais profundamente contaminadas são as que mais ardentemente tentam saciar a sua lascívia obscena: as adúlteras, as fornicadoras e as concubinas dos poderosos. Existe, conforme se lê na Bula Papal, sete métodos pelos quais elas contaminam, através da bruxaria, o ato venéreo e a concepção; primeiro: fomentando no pensamento dos homens a paixão desregrada; segundo: obstruindo a sua força geradora; terceiro: removendo-lhes o membro que serve ao ato; quarto: transmutando-se em bestas pela sua magia; quinto: destruindo a força geradora nas mulheres; sexto: provocando o aborto; sétimo: fornecendo em sacrifício crianças aos Demônios, além de outros animais e frutas da terra, com o que causam enormes males ${ }^{10}$.

Com efeito, as mulheres perseguidas e acusadas eram todas as possivelmente envolvidas em práticas de controle reprodutivo: a gestante, as suas familiares, as suas amigas e, principalmente, a parteira, a figura social que realizava com exclusividade os partos ${ }^{11,12}$ : "as que superam as demais em perversidade" ${ }^{13}$.

Partindo do pressuposto que o momento do surgimento do capitalismo coincide com a Inquisição realizada pela Igreja Católica e a formação do Estado, Federici sustenta que conforme o Estado se consolidava, ele passou a atuar como regulador da relação entre as classes, controlador da reprodução e disciplinador da força de trabalho ${ }^{14}$. A continuidade do controle da reprodução pelo Estado, a partir do século XVI, expressa tanto o recebimento do legado das práticas dos Tribunais da Inquisição como a necessidade do controle para o estabelecimento do capitalismo:

Como destacou Eli Hecksher, "um desejo quase fanático por aumentar a população predominou em todos os países durante o período em que o mercantilismo esteve em seu apogeu, no final do século XVII" [...] mesmo antes do auge da teoria mercantilista, na França e na Inglaterra o Estado adotou um conjunto de medidas pró-natalistas que, combinadas com assistência pública, formaram o embriāo de uma política reprodutiva capitalista. Aprovaram-se lei que bonificavam o casamento e penalizavam o celibato, inspiradas nas que foram adotadas no final do Império Romano com o mesmo propósito. Foi dada uma nova importância à família enquanto instituição chave que assegurava a transmissão da propriedade e a reprodução da força de trabalho. Simultaneamente, observa-se o início do

10 KRAEMER, H.; SPRENGER, J. O martelo das feiticeiras, 2017, p. 90, 99,100.

11 FEDERICI, S. Calibã e a bruxa, 2017, p. 34.

12 Mais tarde, nos séculos XVI e XVII, com a consolidação do exercício do controle reprodutivo pelo Estado por meio de políticas de assistência social em alguns casos e da criminalizaçáo em outros, com a previsão de pena de morte para as mulheres acusadas de infanticídio, as parteiras também respondiam por tal crime, abrindo espaço para a entrada dos médicos nas salas de parto.

13 KRAEMER, H.; SPRENGER, J. O martelo das feiticeiras, 2017, p. 90.

14 FEDERICI, S. Calibã e a bruxa, 2017, p. 164. 
registro demográfico e da intervenção do Estado na supervisão da sexualidade, da procriaçáo e da vida familiar. No entanto, a principal iniciativa do Estado com o fim de restaurar a proporçáo populacional desejada foi lançar uma verdadeira guerra contra as mulheres, claramente orientada a quebrar o controle que elas haviam exercido sobre seus corpos e sua reprodução. [...] Desse modo, a partir de meados do século XVI, ao mesmo tempo que os barcos portugueses retornavam da África com seus primeiros carregamentos humanos, todos os governos europeus começaram a impor penas mais severas à contracepção, ao aborto e ao infanticídio ${ }^{15}$.

A partir do século XVI, inúmeros éditos reais foram decretados na França, Inglaterra e Escócia, objetivando aumentar a vigilância estatal para assegurar que as mulheres não interrompessem a gestação. Elas eram obrigadas a registrar cada gravidez e poderiam ser condenadas à morte caso os bebês falecessem antes do batismo, sendo as mães culpadas ou não pela morte dos filhos. Mulheres sem maridos, encarregadas da criação dos filhos, eram vigiadas publicamente e era ilegal apoiá-las. Nos séculos XVI e XVII, muitas foram processadas pelos Estados, acusadas por violações das normas reprodutivas e infanticídio ${ }^{16}$.

Outro elemento importante a ser retido desse processo histórico que permanece no presente: as mulheres que eram perseguidas, torturadas e mortas eram as da classe camponesa, muito pobres e, dentre elas, as muito idosas (estas fora da idade reprodutiva, porém, parteiras e curandeiras):

Na maioria das áreas da Europa, as acusadas eram muito pobres e seus acusadores estavam em melhor situação do que elas. Embora a maioria dos acusadores fossem vizinhos que também viviam na pobreza, ainda assim possuíam mais bens do que as suas vítimas. A feiticeira era, em muitos casos, a mais pobre entre os pobres, dependendo de seus vizinhos, para não morrer de fome. [...] No século XVI, os pobres estavam se tornando ainda mais pobres; mais camponeses foram forçados a esmolar ou a roubar para sobreviver. As mulheres mais velhas e solitárias, especialmente vulneráveis a esse esmagamento econômico, começaram a ser vistas como incômodas. Quando não as ajudavam, as pessoas se sentiam culpadas, um estado inconfortável que era frequentemente exacerbado quando as mendigas as amaldiçoavam por sua recusa. Entáo, quando uma desgraça acontecia, as pessoas voltavam-se contra as mendigas ${ }^{17}$.

A condição das mulheres na estruturação da sociedade patriarcal ${ }^{18}$ na Era Moderna, apresentada por Federici, atualiza o enunciado de Engels acerca da grande derrota

15 FEDERICI, S. Calibã e a bruxa, 2017, p. 173,174.

16 FEDERICI, S. Calibã e a bruxa, 2017, p. 176.

17 BARSTOW, A. L. Chacina de feiticeiras: uma revisão histórica da caça às bruxas na Europa, 1995, p. 45.

${ }_{18}$ A autora deste artigo compreende patriarcado não apenas como uma norma da relaçáo entre homens e mulheres, hierárquica e de domínio social das mulheres pelos homens, mas também como uma lógica. Uma lógica de dominação que se expressa na dominação de gênero, na apropriação da terra, na organizaçáo do Estado, na organização das relaçóes sociais. Uma apresentação mais detida dessa questấo ultrapassa o objeto deste artigo. 
histórica das mulheres, em razão da perda do controle da reprodução e, simultaneamente, amplia a análise do capitalismo realizada por Marx, pois insere nos pressupostos de funcionamento do capitalismo a opressão das mulheres. Assim, Federici demonstra como o capitalismo coloca a seu serviço as estruturais sociais patriarcais conjugadas com a formação dos Estados Modernos, produzindo uma triangulação ${ }^{19}$ necessária entre capitalismo, Estado e patriarcado, na qual o Estado, ao controlar a reprodução, assujeita as mulheres à função reprodutiva - fornecedoras de mão de obra, por parte da classe trabalhadora, e fornecedoras dos herdeiros, por parte da classe dominante - e, ainda, promove a continuidade da ruptura da unidade da classe trabalhadora ao sustentar um emaranhado de violências socialmente legitimadas contra as mulheres ${ }^{20}$, figurando a sua criminalização e penalização por condutas antirreprodutivas, uma das expressóes dessas violências.

A retomada do controle da reprodução pelas mulheres implicaria profundas transformaçóes na organização da política e no fortalecimento da luta pela fundação de uma nova sociabilidade democrática anticapitalista.

\section{OS ARGUMENTOS JURÍDICOS DO HABEAS CORPUS 124.306}

Posto o problema relativo ao controle reprodutivo promovido pelo Estado Moderno, cujas raízes são concomitantes ao desenvolvimento do capitalismo, será analisado nas próximas seçóes, o estado do debate no campo jurídico no Brasil, sobre a descriminalização da prática do aborto e o direito das mulheres à interrupção voluntária da gravidez, com base nos votos do Habeas Corpus 124.306; nos debates ocorridos na Audiência Pública realizada nos dias 03 e 06 de agosto de 2018, sobre o tema objeto da Arguição de Descumprimento de Preceito Fundamental (ADPF) 442, em trâmite no Supremo Tribunal Federal e no estudo analítico realizado pelo Núcleo de Promoção e Defesa dos Direitos da Mulher pela Defensoria Pública do Estado de São Paulo (NUDEM-DPESP) a partir da propositura de 30 Habeas Corpus em açóes penais e medidas socioeducativas em trâmite no Tribunal de Justiça do Estado de São Paulo (TJSP), nos quais mulheres figuravam como rés, acusadas da autoria da tentativa ou prática de aborto.

\footnotetext{
19 A bem da verdade, trata-se de uma relação quadricular: Estado Moderno, lógica de dominação do capitalismo, lógica de dominação do patriarcado e lógica de dominação do racismo. Uma apresentação mais detida dessa relação ultrapassa o objeto deste artigo.

20 Ultrapassa os limites deste estudo desenvolver a fórmula emaranhado de violências socialmente legitimadas contra as mulheres, pois essa ideia é sustentada não apenas na análise apresentada por Federici sobre o fenômeno da caça às bruxas, mas também em uma longa trajetória legislativa que, desde o Código de Hamurabi até o século XX, legitimou, de variadas maneiras, a punição das mulheres pelos homens, inclusive com a morte, no que diz respeito a condutas sexuais. É suficiente para o momento, concentrarmo-nos na concepçáo de que a criminalização da interrupção da gestação é um dos aspectos deste emaranhado de violências socialmente legitimadas contra as mulheres.
} 


\section{$1.1 \mathrm{O}$ caso concreto}

Os pacientes do Habeas Corpus 124.306 são processados nos autos do processo de número 0312390-33.2014.8.19.0001, em trâmite perante o Juízo da $4^{\mathrm{a}}$ Vara Criminal da Comarca de Duque de Caxias/RJ, acusados de provocar aborto com consentimento da gestante (art. 126 CP) e outras tipificações penais. Em 21/03/2013, o Juízo concedeu a liberdade provisória aos pacientes. Em 25/02/2014, a $4^{\mathrm{a}}$ Câmara Criminal deu provimento ao recurso interposto pelo Ministério Público do Estado do Rio de Janeiro (MPRJ), decretando a prisão preventiva dos pacientes, com fundamento na garantia da ordem pública e na necessidade de assegurar a aplicação da lei penal. Face a essa decisão, a defesa impetrou Habeas Corpus (HC) perante o Superior Tribunal de Justiça (STJ), que não foi conhecido pela Corte, porém, o mérito foi analisado e a decretação da prisão preventiva foi mantida. Assim, o Habeas Corpus 124.306 foi impetrado perante o Supremo Tribunal Federal (STF), requerendo a concessão de ordem para desconstituir a decisão do STJ que manteve a prisão preventiva dos pacientes, antes do trânsito em julgado do processo principal.

As bases jurídicas arguidas pela defesa consistiram em requerer que fosse conferida a interpretação conforme a Constituição dos artigos 124 a 126 do Código Penal (CP), que tipificam o crime de aborto para excluir do seu âmbito de incidência a interrupçáo voluntária da gestação efetivada até o primeiro trimestre e para afirmar: i) o entendimento da Turma de que a criminalização do aborto é incompatível com os direitos fundamentais, a saber, direitos sexuais e reprodutivos das mulheres, pois elas não podem ser obrigadas pelo Estado a manterem uma gestação indesejada, bem como o Estado tem o dever de promover o amplo acesso à saúde pública a todas as cidadás e cidadãos; ii) a preservação da autonomia das mulheres no que diz respeito a suas escolhas existenciais; iii) a preservação da integridade física e psíquica das gestantes; iv) a promoção da igualdade jurídica de gênero, uma vez que os homens náo engravidam e a equiparação plena de gênero depende do respeito a vontade das mulheres nessa matéria; v) que se trata de direito público à saúde e os efeitos da criminalização da conduta afetam sobremaneira as mulheres pobres que não têm acesso a médicos e clínicas privadas, multiplicando-se os casos de automutilação, lesôes graves e óbitos; vi) a violação ao princípio da proporcionalidade, pois a criminalização não é adequada para tutelar a vida do nascituro, visto o número de abortos praticados no país, implicando apenas o impedimento da realização da prática segura; vii) a compreensão de que o Estado possui meios mais eficazes do que a criminalização para a prevenção da prática, tais como promoção de educação sexual, distribuição de contraceptivos e amplo amparo à mulher que deseja ter filhos, mas se encontra em condiçóes adversas; viii) o entendimento de que a criminalização gera custos sociais ainda maiores do que seus benefícios, sejam: problemas de saúde pública e óbitos.

Trata-se, portanto, de precedente importante do STF referente à defesa dos direitos sexuais e reprodutivos das mulheres ao afirmar a inconstitucionalidade da incidência do tipo penal do aborto no caso de interrupção voluntária da gravidez no primeiro trimestre.

O Relator do $H C$, Ministro Marco Aurélio, admitiu a impetração do referido instrumento legal como substitutivo do Recurso Ordinário Constitucional, considerando que o $H C$ 
é a via direta para garantia da liberdade de ir e vir quando ameaçada por mandado de prisão expedido ou em iminência de o ser; assim, concedeu a ordem da desconstituição do decreto de prisão preventiva, mas náo se manifestou sobre a inconstitucionalidade dos artigos 124 a 126 da Lei Penal.

Os fundamentos para concessão da ordem apresentados pelo Ministro foram: i) a tentativa de fuga do flagrante é exercida como direito natural e deve ser entendida como afirmaçáo do direito de não autoincriminação, conforme o art. 8, item 2, alínea "g" do Pacto de São José da Costa Rica, não configurando justificativa para determinação da prisão preventiva; ii) não se encontravam presentes os requisitos processuais que autorizam a determinação da prisão preventiva, tais sejam, risco à ordem pública, à ordem econômica, à instruçáo do processo ou à aplicação da lei penal, tendo em vista que no caso em análise a instrução processual transcorria normalmente; iii) a decretação da prisão preventiva quando ausentes os requisitos processuais que a autoriza, viola o princípio da presunção de inocência.

O Ministro Luís Roberto Barroso requereu voto-vista e manifestou tanto a possibilidade de, excepcionalmente, conceder de ofício a desconstituição da decretação da prisão preventiva, considerando a inadequaçáo da via eleita $-H C$ - como para analisar a inconstitucionalidade da criminalização da interrupção voluntária da gestação até a $12^{\mathrm{a}}$ semana, pois um dos argumentos elencados para fundamentar a prisão preventiva foi a invocação genérica da gravidade abstrata do delito de provocar aborto com o consentimento da gestante.

No que diz respeito à matéria processual, o Ministro Luís Roberto Barroso acompanhou o Ministro Relator, no sentido de não ser admissível a decretação da prisão preventiva quando ausentes os requisitos exigidos pelo Código de Processo Penal (CPP). Quanto à análise da inconstitucionalidade da tipificaçáo penal prevista no art. 126 do CP (provocar aborto com o consentimento da gestante), o Ministro argumentou que: i) a criminalização da conduta viola os direitos fundamentais das mulheres; ii) expressa violação ao princípio da proporcionalidade; iii) há meios mais eficazes do que a criminalização para tratar a questão, cabendo ao Estado assegurar que o procedimento seja raro e seguro.

\subsection{Da violaçáo aos direitos fundamentais das mulheres}

O Ministro Luís Roberto Barroso inicia a exposição de suas razões afirmando que os direitos fundamentais devem ser entendidos como direitos humanos incorporados ao ordenamento constitucional, devendo ser respeitados por todos os Poderes estatais, sendo certo que dos direitos fundamentais decorrem deveres de abstração e atuação por parte do Estado e da sociedade. Outra característica essencial dos direitos fundamentais é que eles devem ser afirmados e respeitados mesmo em oposição à maioria e que são dotados de aplicabilidade direta e imediata, o que legitima a atuação do STF para sua proteção ou quando houver omissão legislativa, uma hipótese em questáo. Quando direitos fundamentais entram em rota de colisão entre si, a solução deve valer-se do princípio da razoabilidade ou proporcionalidade. No caso em análise, estão em colisão o direito à vida do nascituro e os direitos sexuais e reprodutivos das mulheres. 
O Ministro, então, sustenta que a criminalização da interrupção voluntária da gestação é compreendida, majoritariamente no mundo democrático e desenvolvido, como grave violação a diversos direitos fundamentais das mulheres, tais sejam: i) autonomia, pois viola o núcleo essencial da liberdade individual, protegida pelo princípio da dignidade humana e, sendo assim, este núcleo deve ser protegido das interferências do Estado e da sociedade; ii) integridade física e psíquica das mulheres, diretamente relacionadas ao direito à saúde e à segurança; iii) direitos sexuais e reprodutivos, pois o tratamento penal dado ao tema no Brasil afeta a capacidade de autodeterminaçáo reprodutiva da mulher, sendo obrigada pelo Estado a manter uma gestação indesejada; iv) igualdade de gênero, pois, em razão da histórica posição de subordinação e opressão das mulheres pelos homens, caberia ao Direito neutralizar as injustiças históricas, econômicas e sociais, assegurando às mulheres o direito de decidir sobre a reprodução. Por fim, o Ministro afirma que a criminalização da conduta produz efeitos ainda piores para as mulheres pobres, agravando a discriminação social. Tendo em vista que, em razão da criminalização, o Estado deixa de oferecer às cidadãs os cuidados necessários para a realização segura do procedimento, isso induz elas a utilizarem-se de métodos clandestinos e inseguros, configurando o aborto como a quarta causa de mortalidade materna no Brasil.

\subsection{Violaçáo ao princípio da proporcionalidade}

Sobre esse aspecto, argumentou o Ministro Luís Roberto Barroso: i) o legislador, ao produzir leis que criminalizam condutas, deve observar o respeito aos direitos fundamentais dos acusados tanto no plano material quanto no plano processual e, no momento da elaboração legislativa, deve considerar o compromisso de proteção para com a sociedade, resguardando valores, bens e direitos fundamentais dos seus integrantes. Quando o objeto da lei penal incidir sobre restriçóes aos direitos fundamentais, o princípio da proporcionalidade é de observância obrigatória, pois é ele que proíbe o excesso e que avalia a insuficiência do dispositivo legal; ii) sobre a criminalização da interrupção voluntária da gravidez, é preciso observar que os referidos artigos proibitivos datam de 1940, devendo ser revistos à luz dos novos valores constitucionais resguardados pela Constituição da República de 1988; iii) decorrem do princípio da proporcionalidade a avaliação quanto à adequação, necessidade e proporcionalidade em sentido estrito, ou seja, se a via penal é adequada ou não para tutelar o direito à vida do feto.

Quanto à adequação, o Ministro assevera que a criminalização da interrupção voluntária da gravidez é ineficaz para resguardar a vida do feto, pois não resulta na redução da prática e, por outro lado, implica gravemente práticas inseguras e altas taxas de mortalidade materna. Quanto à necessidade, avalia-se que há outros meios mais eficazes e menos restritivos aos direitos fundamentais das mulheres como, por exemplo, educação sexual; ampliação do acesso aos métodos contraceptivos; e expansão das políticas públicas de suporte às mães - acesso às creches, assistência social, saúde e educação -, de modo a proporcionar às mulheres os serviços públicos necessários para criação dos filhos. Por último, quanto à proporcionalidade em sentido estrito, a via penal para o tratamento da questão causa um único efeito que é a realização de abortos inseguros, 
com alto custo social, tanto para o Sistema Público de Saúde quanto para a vida das mulheres e a criminalização das mulheres pobres.

O Voto do Ministro Luiz Edson Fachin também se limitou à análise preliminar sobre a admissibilidade do $H C$, manifestando-se contrário; porém, acompanhando os demais, concedeu a ordem de ofício. Ele não analisou a inconstitucionalidade dos artigos penais em questáo, mas registrou em ata que na semana do julgamento do referido $H C$ foi divulgada a Carta Apostólica Misericordia et misera do Papa Francisco, onde foi acentuada a possibilidade de absolvição, por parte da Igreja Católica, de mulheres e profissionais de saúde que, porventura, tenham alguma participação na interrupção da gravidez após a confissão.

A Ministra Rosa Weber apresentou voto concorrente, acompanhando o voto-vista do Ministro Luís Roberto Barroso que trouxe argumentos adicionais ao debate sobre a experiência comparada da questáo, apresentando os seguintes precedentes: i) da Suprema Corte dos Estados Unidos, no caso Roe versus Wade, no qual foi decidido pela inconstitucionalidade da criminalização da interrupção da gravidez, estabeleceu-se critérios para a disciplina legislativa do aborto: até o primeiro trimestre, a conduta é permitida e de livre escolha da mulher; até o segundo semestre, o Estado poderia regular o exercício do direito, com objetivo de proteger a vida da mulher gestante; e no último trimestre, a conduta é proibida; ii) da Corte Interamericana de Direitos Humanos, no caso Artavia Murillo y outros versus Costa Rica, no qual analisou-se a possibilidade da fertilização in vitro, e, para tanto, enfrentou a necessidade de manifestar-se sobre a tutela dos direitos e da autonomia reprodutiva das mulheres e sobre a natureza dos direitos do embrião e do feto. A decisão foi no sentido de afirmar os direitos reprodutivos das mulheres e sua autonomia, bem como asseverar que o direito à vida do embriāo e do feto não é um direito absoluto, mas gradual e incremental, conforme seu desenvolvimento, cabendo, portanto, exceçóes; iii) da Corte Europeia de Direitos Humanos, nos casos Paton versus United Kingdom; Vo versus France; Evans versus United Kingdom; e $A, b$ and $C$ versus Ireland, nos quais igualmente se consolidou que a proteção do direito à vida do embrião e do feto náo é absoluta, devendo haver proporcionalidade entre a proteção desses e a proteção dos demais direitos, notadamente, os direitos da mulher e sua autonomia reprodutiva.

\section{DEBATE SOBRE A DESCRIMINALIZAÇÃO DA INTERRUPÇÃO VOLUN- TÁRIA DA GRAVIDEZ NO BRASIL - AUDIÊNCIA PÚBLICA REALIZADA NA ADPF 445}

A Arguição de Descumprimento de Preceito Fundamental (ADPF) 445 foi protocolizada junto ao STF em 22/03/2017, pelo Partido Socialismo e Liberdade (PSOL), tendo como Relatora a Ministra Rosa Weber, objetivando a declaração de não recepção parcial pela Constituição da República de 1988 dos artigos 124 e 126 do Código Penal Brasileiro, a fim de excluir de seu âmbito de incidência a interrupção voluntária da gestação realizada nas primeiras 12 semanas. Os referidos dispositivos penais, oriundos do CP de 1940, estariam em desacordo com a Constituição, pois são incompatíveis: i) com a dignidade da pessoa humana; ii) com a cidadania das mulheres; iii) com o dever de promoçáo da não discriminação como princípio fundamental da República; iv) com os direitos fundamentais das mulheres à vida, à liberdade, à integridade física e psicológica, à igualdade, à 
proibição de tortura ou tratamento desumano ou degradante, à saúde e ao planejamento familiar (Constituição, art. $1^{\circ}$, incisos I e II; art. $3^{\circ}$, inciso IV; art. $5^{\circ}$, caput e incisos I e III; art. $6^{\circ}$, caput, art. 96 e art. 226, inciso 7).

A pretensão, portanto, visa garantir às mulheres o direito constitucional à interrupção da gestaçáo nas primeiras 12 semanas, de acordo com a sua autonomia, sem a necessidade de qualquer forma de permissão específica do Estado, bem como garantir o acesso aos procedimentos médicos necessários pelo Sistema Público de Saúde, assegurando, igualmente, aos profissionais de saúde o direito de realizar o procedimento por meios seguros.

Dos dias 3 a 6 de agosto de 2018, foi realizada a Audiência Pública junto ao STF, visando promover o amplo debate sobre o tema, incluindo diversos setores da sociedade, tais como: especialistas, institutos científicos nacionais e internacionais, associaçóes médicas, Ministério da Saúde, universidades, organizaçóes religiosas, diversos institutos e conselhos vinculados a pesquisas jurídicas, Defensorias Públicas Estaduais de São Paulo e Rio de Janeiro, bem como a Defensoria Pública da União e a Frente Parlamentar em Defesa da Vida e da Família. Cada um dos representantes das respectivas instituiçóes e os participantes individuais (náo vinculados a qualquer instituição) tiveram o tempo de 20 minutos para apresentarem suas exposiçóes ${ }^{21}$.

Ao todo, foram realizadas 54 intervençôes, divididas em quatro seçôes: área médica e científica - 14 intervençôes; área social (movimentos sociais e outras associaçôes) - 16 intervençōes; área religiosa - 11 intervençōes, contando com representantes das religiōes: católica, evangélica, batista, luterana, espírita, israelita e muçulmana; e área jurídica - 13 intervençóes ${ }^{22}$.

Majoritariamente, as manifestaçóes foram favoráveis sobre os seguintes tópicos: i) competência do STF para decidir sobre a questão; ii) necessidade de declarar a inconstitucionalidade dos artigos 126 e 128 do CP, conferindo-lhes a devida interpretação conforme a constituição, portanto, a maioria das entidades sociais e institucionais ouvidas manifestou-se a favor da descriminalização da prática da interrupção da gravidez até a 12a semana de gestação.

A seção da área médica e científica ${ }^{23}$ apresentou os dados que confirmam as teses jurídicas em defesa das mulheres acusadas da prática de aborto: i) a criminalizaçáo não coíbe a conduta; ii) mulheres de todas as classes realizam abortos; iii) a consequência efetiva da criminalização é colocar em risco a vida das mulheres mais vulneráveis, implicando a morte de muitas dessas; iv) criminalizar a prática do aborto é, do ponto de vista do Estado, descumprir o dever de cuidado exigido como direito de toda cidadã e cidadáo, pois obriga as mulheres a

\footnotetext{
${ }^{21}$ A gravação da Audiência Pública está disponível no canal do STF no YouTube e a transcrição das exposições se encontra em relatório no link: https://bit.ly/3gYxprM.

22 Algumas instituiçôes apresentaram dois ou mais representantes que compartilharam o tempo de 20 minutos de exposição, tendo sido contabilizado, neste artigo, como número de intervençóes por seção, apenas as instituiçóes representadas e não as falas individualizadas quando a instituição apresentou mais de um representante.

${ }^{23}$ Das exposiçóes dessa seção, oito manifestaram-se a favor da descriminalizaçáo do aborto e um contrário, curiosamente, trata-se de uma exposição individual, não representativa de nenhuma entidade, embora o expoente, o médico carioca Raphael Câmara, tenha se posicionado como porta-voz dos médicos.
} 
recorrerem a métodos que colocam em risco a própria integridade física e a vida, negando-lhes a assistência médica necessária. Uma informação relevante foi apresentada pelo médico José Gomes Temporão, representante da Academia Nacional de Medicina: nenhum outro tema de saúde, considerando a possibilidade de evitar ou diminuir os danos, é tratado desta forma, ou seja, com a negativa do cuidado e com a criminalizaçáo ${ }^{24}$. Nessa seção, apenas uma manifestação individual, do médico Raphael Câmara, foi contrária à descriminalização da prática do aborto e as razóes limitaram-se a negar todos os dados apresentados pelos colegas relativos aos números de mortes, de mulheres presas e que indicam a redução da prática em países que possuem uma legislação menos restritiva, bem como colocar em dúvida a segurança do método abortivo quando realizado em condiçóes adequadas.

Na seção da área social, constituída por organizaçóes e movimentos sociais ${ }^{25}$, além de corroborarem os principais argumentos trazidos pela comunidade científica, apresentaram argumentos adicionais sobre a subnotificação dos casos de óbito em decorrência do aborto realizado sem as condiçóes adequadas para a saúde da mulher, pois o aborto é quase impossível de ser descoberto como causa mortis se náo for informado pela mulher antes do óbito e trata-se de mulheres que não informam a gravidez, muito menos que induziram o aborto ${ }^{26}$. Houve a exposição realizada por Adriana Abreu Magalhães Dias, representante do Instituto Baresi, afastando o argumento de que a legalização da prática do aborto efetivaria uma eugenia ao possibilitar às mulheres a decisão da continuidade da gestaçáo caso o feto apresente doenças incapacitantes ${ }^{27}$. Dentro dessa seção, destaca-se, ainda, a exposição feita por Viviane Petinelli, representante do Instituto de Políticas Governamentais, manifestando-se contrária à descriminalização, apresentando um argumento oposto ao apresentado anteriormente pela comunidade médica e científica sobre a redução da prática de abortos quando a conduta é descriminalizada. Entretanto, os representantes das organizaçóes de saúde e científicas argumentam, com base em dados recolhidos de diversos países que: i) países com taxas de aborto mais elevadas são aqueles nos quais a prática é criminalizada; ii) a mortalidade materna relacionada a abortos inseguros é praticamente zero em países de alta renda e de reduzida desigualdade social, no caso de países em que a prática seja legalmente restritiva ou com leis permissivas, fator que explicita como a criminalização configura-se como uma grave situação de injustiça e desigualdade ${ }^{28}$. A representante do Instituto de Políticas Governamentais contra-argumentou alegando que a legalização da prática do aborto produz uma maior incidência do método e pode implicar, a médio e longo prazo, um déficit demográfico, provocando uma reduçáo da taxa de fecundidade, desequilibrando a administração pública demográfica, bem como produzindo uma superoneração do Sistema Público de

24 BRASIL. Supremo Tribunal Federal. Audiência Pública. Interrupçáo voluntária de gravidez. ADPF 442, 2018, p. 46.

25 Oito exposições favoráveis à descriminalização e três contrárias.

26 BRASIL. Supremo Tribunal Federal. Audiência Pública. Interrupção voluntária de gravidez. ADPF 442, 2018, p. 200.

27 BRASIL. Supremo Tribunal Federal. Audiência Pública. Interrupção voluntária de gravidez. ADPF 442, 2018, p. 133-145.

28 BRASIL. Supremo Tribunal Federal. Audiência Pública. Interrupção voluntária de gravidez. ADPF 442, 2018, p. 61. 
Saúde ${ }^{29}$. As outras organizaçóes sociais que se manifestaram contrárias à descriminalização da prática do aborto os argumentos giraram ao redor da defesa do feto abortado como um valor superior aos direitos fundamentais das mulheres ${ }^{30}$.

$\mathrm{Na}$ seção da área religiosa, a única em que as exposiçóes contrárias à descriminalização superaram as exposiçōes a favor ${ }^{31}$, destacam-se os seguintes aspectos: representantes católicos, evangélicos (Assembleia de Deus e Batistas) e espíritas manifestaram-se contra a descriminalização, apresentando exclusivamente argumentos científicos e jurídicos, e não argumentos religiosos-morais - pressupostos científicos discutíveis sobre o início da vida a partir da fecundação e jurídicos que asseguram o direito à vida como fundamental do nascituro. Apenas Moshin Ben Moussa, representante da Federação das Associaçôes Muçulmanas do Brasil (FRAMBRAS) expressou argumentos teológicos, dentre todos os que realizaram exposiçôes, para manutenção da legislação penal brasileira com base na legislação islâmica ${ }^{32}$. Quanto aos argumentos favoráveis à descriminalização, assim se manifestaram: Maria José Fontelas Rosado Nunes, representante do Católicas pelo Direito de Decidir; Instituto dos Estudos da Religião, representado por Lusmarina Campos, pastora da Igreja Evangélica de Confissão Luterana no Brasil ${ }^{33}$; e a Confederação Israelita do Brasil, representada pelo Rabino Michel Schlesinger. A representante do Católicas pelo Direito de Decidir argumentou, dentre outras razōes, que a criminalização da prática implica pena de morte para as mulheres; o Rabino aconselhou que o Estado deve acolher as mulheres nas suas escolhas; e Lusmarina, pastora da Igreja Evangélica de Confissão Luterana, a única a trazer para o debate o lembrete da perseguição histórica das mulheres realizada pela Igreja Católica durante a Inquisição, afirmou que os argumentos contrários à descriminalização são, antes de tudo, argumentos cristãos patriarcais:

Há séculos, um cristianismo patriarcalizado é o responsável por penalizar e legitimar a morte de mulheres. A criminalização religiosa das mulheres

\footnotetext{
29 BRASIL. Supremo Tribunal Federal. Audiência Pública. Interrupção voluntária de gravidez. ADPF 442, 2018, p. 210-216.

30 BRASIL. Supremo Tribunal Federal. Audiência Pública. Interrupção voluntária de gravidez. ADPF 442, 2018, p. 145-157. O argumento em defesa do feto abortado também aparece na exposição do primeiro representante da Conferência Nacional dos Bispos (CNB) - páginas 302 a 308.

31 Oito exposições contrárias à descriminalização e três a favor.

32 BRASIL. Supremo Tribunal Federal. Audiência Pública. Interrupção voluntária de gravidez. ADPF 442, 2018, p. 430-436.

33 Lusmarina Campos é teóloga pelo Seminário Teológico Batista do Sul do Brasil; Bacharel em Direito e Ciências Sociais; Mestra em Direito e Doutoranda pela Faculdade Nacional de Direito da Universidade Federal do Rio de Janeiro; pastora da Igreja Evangélica de Confissão Luterana no Brasil; trabalhou no Instituto de Estudos da Religiáo e, atualmente, é colaboradora desta instituição. Ela foi presidente do Conselho de Igrejas Cristãs do Estado do Rio de Janeiro e, hoje, é membro de sua diretoria, assim como do Conselho Estadual de Defesa e Promoção da Liberdade Religiosa do Estado do Rio de Janeiro. Possui trajetória internacional pelo movimento ecumênico do Conselho Mundial de Igrejas e da Federação Luterana Mundial, organizaçōes engajadas na defesa da democracia, dos direitos humanos, da liberdade religiosa e da justiça de gênero; ela compóe o comitê organizador da Consulta Global de Comemoração do 20 Aniversário da Década Ecumênica de Solenidade das Igrejas com as Mulheres, do Conselho Mundial de Igrejas, realizada de 1 a 6 de outubro de 2018, na Jamaica. Seu trabalho conecta direitos humanos e teologia, a partir de uma perspectiva de gênero.
} 
por causa do aborto necessita ser colocada neste contexto histórico. [...] por que as tradiçóes religiosas que são construções históricas insistem em disseminar e reproduzir a misoginia controlando os corpos das mulheres e penalizando-as psiquicamente por causa do suposto pecado e da culpa, e também criminalmente? As inquisiçôes contra mulheres continuam, mesmo travestidas por outras faces e formas. Outrora, foram as fogueiras reais; hoje, as fogueiras simbólicas, mas não menos perversas, que insistem através de um poder religioso, que age contra a dignidade das mulheres, via poder político, e se mantém institucionalmente ${ }^{34}$.

Lusmarina prosseguiu sustentando que a descriminalização da prática do aborto efetiva o direito à igualdade, preserva a liberdade religiosa e de consciência, realiza o princípio da laicidade do Estado e efetiva a democracia.

Na última seção, da área jurídica, na qual a Defensoria Pública da União figura como amicus curiae, as entidades e instituiçóes públicas que participaram do debate posicionaram-se favoráveis à descriminalização e afirmaram, em uníssono, que a descriminalização é a interpretação devida à luz da Constituição da República, bem como é conforme as diretrizes dos Direitos Humanos internacionais ${ }^{35}$. Contrapuseram os argumentos que defendem a criminalização da prática, dizendo que: i) há uma negação das estatísticas ${ }^{36}$; ii) os defensores da punição desconsideram a análise conforme a Constituição da República de 1988 e os compromissos internacionais do Brasil, no âmbito dos direitos humanos internacionais; iii) a criminalização pressupóe o direito à vida do feto como superior ao direito da vida das mulheres.

\subsection{Estudo do Núcleo de Promoçáo e Defesa dos Direitos das Mulheres - Defensoria Pública Estadual de Sáo Paulo}

O Núcleo de Promoção e Defesa dos Direitos da Mulher pela Defensoria Pública do Estado de São Paulo (NUDEM-DPESP) foi criado em 2008 em decorrência de reivindicaçóes do movimento de mulheres de SP pela criação de um espaço institucional no âmbito da defensoria para buscar a garantia dos seus direitos. Este pleito foi realizado durante o primeiro ciclo de conferências das defensorias paulistas em 2007. O NUDEM-DPESP atua em diversas situaçóes de violaçóes de direitos humanos das mulheres, em uma perspectiva coletiva, fomentando e cobrando políticas públicas, bem como atuando na promoção da educação em direitos e na assessoria de Defensores. As temáticas de atuação do NUDEM são: violência doméstica; violência obstétrica; violência sexual; assédio; cyberbullying; direito sexual e reprodutivo; não exigência de exames ginecológicos em concursos públicos; direito das profissionais do sexo; direito de mulheres criminalizadas, em situação de prisão e em situação de rua; garantia ao aborto legal; e luta pela descriminalização e legalização da prática da interrupção da gravidez; dentre outras, com foco no atendimento da popu-

\footnotetext{
34 CAMPOS, L. Relatório das exposiçóes realizadas na Audiência Pública, 2018, p. 356-357.

35 Dez exposições favoráveis à descriminalização e três contrárias.

36 BRASIL. Supremo Tribunal Federal. Audiência Pública. Interrupção voluntária de gravidez. ADPF 442, 2018, p. 493, 508.
} 
lação mais vulnerável onde os marcadores sociais de desigualdade de raça, classe, sexualidade e gênero se combinam de forma extremamente danosa ${ }^{37}$.

Em 2017, o NUDEM-DPESP impetrou 30 Habeas Corpus em açóes penais e medidas socioeducativas em trâmite no Tribunal de Justiça do Estado de São Paulo (TJSP), nos quais mulheres figuravam como rés, acusadas da autoria da tentativa ou prática de aborto. A partir desses $H C$ foi produzido um estudo analítico com o perfil majoritário das mulheres processadas; a maneira como elas chegaram ao sistema de segurança pública; e a situação processual. Em relação ao perfil dominante, constatou-se que se tratavam de mulheres: i) jovens, em idade reprodutiva; ii) mães, cuidadoras, provedoras de filhos e solteiras; iii) em vulnerabilidade econômica, sendo as principais provedoras das famílias e nenhuma com remuneraçáo superior a $\mathrm{R} \$ 2.500,00$; iv) de baixa escolaridade, realizando atividades profissionais como: auxiliares administrativas, atendentes, auxiliares de produção, balconistas, calçadistas, ajudantes em geral, operadoras de caixa, ajudantes de cozinha, feirantes, manicures e vendedoras; v) moradoras das periferias; vi) rés primárias e com bons antecedentes.

Essas mulheres chegaram ao sistema de segurança pública por meio da prática de denúncia realizada pelos profissionais de saúde em violação ao Código de Ética Médica e à legislação. Em relação à situação processual, foi constatado que, até o momento de intervençâo da referida Defensoria, pela impetração de Habeas Corpus com a finalidade de trancamento das açóes penais em curso, não havia sido interposto qualquer recurso ou $H C$ em defesa das mulheres acusadas. Todas eram vítimas de violaçóes aos direitos à intimidade, à privacidade, ao devido processo legal e ao efetivo acesso à justiça. Em três casos, não havia prova da materialidade da conduta imputada como criminosa. As teses defensivas apresentadas foram: i) atipicidade da conduta diante da inconstitucionalidade da criminalização, devendo ser reconhecida por meio do controle de constitucionalidade realizado pelo Tribunal; ii) trancamento da ação penal por ausência de justa causa, pois a persecução criminal era baseada em notícia crime ou instrução probatória decorrente da quebra de sigilo profissional por parte dos servidores públicos vinculados à saúde; iii) em alguns casos, ausência de prova da materialidade da conduta imputada. Dois dos casos se tratavam da realização de aborto legal.

Dos vinte e cinco $H C$, vinte e três tiveram a ordem denegada; um não foi conhecido; e um foi prejudicado. Cinquenta e cinco desembargadores participaram desse conjunto de $H C$, desses, apenas três eram desembargadoras (5,45\%). Nos cinco casos em que se concedeu a ordem, três tiveram participação de desembargadoras (60\%). Dentre eles, quatro casos havia falta de justa causa por ausência de materialidade delitiva, pois não havia indício da prova de gestação, aborto ou provocação do aborto; e um havia falta de justa causa, pois a notícia crime partiu de um profissional de saúde, reconhecida a violaçáo do dever de sigilo médico ${ }^{38}$.

\footnotetext{
37 SÃO PAULO. 30 habeas corpus: a vida e o processo de mulheres acusadas da prática de aborto em São Paulo, 2018.

${ }^{38}$ O estudo realizado pela Defensoria Geral do Estado do Rio de Janeiro (DPGE), em 2018, Entre a morte e a prisáo: quem são as mulheres criminalizadas pela prática do aborto no Rio de Janeiro, apresenta os mesmos resultados do estudo do NUDEM-DPESP, exposto neste trabalho.
} 


\section{CONSIDERAÇÓES FINAIS}

O estudo do NUDEM-DPESP demostra um dos paradoxos da sociedade brasileira. Por um lado, tanto o acórdáo do $H C 124.306$ quanto as manifestações majoritárias proferidas na Audiência Pública realizada no âmbito das discussôes da ADPF no 442 parecem demonstrar uma tendência à consolidaçáo do entendimento de que os artigos 124 a 126 do Código Penal devem ser declarados inconstitucionais, à luz da interpretação conforme a Constituição da República de 1988. Por outro lado, no nível público institucional que mantém relação direta com a populaçáo, seja o judiciário, seja o serviço público de saúde, a suspeita ou a prática do aborto é efetivamente criminalizada, exclusivamente em relação às mulheres pobres, com a realização, inclusive, de diversas violaçôes aos direitos das mulheres, especialmente, a quebra do sigilo profissional médico e de outros profissionais da saúde, com inúmeros casos em que elas são algemadas ainda nos leitos dos hospitais. O posicionamento do médico Raphael Câmara na Audiência Pública da ADPF 442 é sintomático sobre o problema quando ele se apresenta em nome da classe médica:

Eu estou aqui pelos médicos. Foram os médicos que mandaram centenas de e-mails para eu estar aqui para representar a opiniáo do médico. Eu vejo vários médicos aqui, todos a favor da liberação do aborto, mas eles não representam a gente!

$\mathrm{Na}$ Argentina, grupos de médicos se recusam a fazer aborto, médico, mesmo que a lei passe. Quem vai fazer esses abortos? Vamos dizer que liberem. Quem vai fazer? A maioria vai alegar objeção de consciência ${ }^{39}$.

Isso sem mencionar os inúmeros obstáculos encontrados pelas mulheres nos casos de aborto legal e a dificuldade de efetivarem o acesso a esse direito. Estudos demonstram que cerca de 7\% dos casos de estupro resultam em gravidez. Nesses casos, as mulheres têm o direito de interromper a gestação. No entanto, apenas $67,4 \%$ tiveram acesso ao serviço de aborto legal na rede pública de saúde. É bastante conhecido o caso da menina de nove anos, residente no Agreste pernambucano, estuprada pelo padrasto e grávida de gêmeos. Obtida a autorizaçáo judicial, o arcebispo de Olinda e Recife pronunciou: "o crime que o padrasto cometeu era grave, mas não tanto quanto o aborto" e excomungou a máe, a equipe médica, o juiz, a promotora e a assistente social envolvidos no processo. $\mathrm{O}$ hospital infantil e maternidade local se recusaram a fazer o procedimento por pressão da igreja e religiosos. ONGs e movimentos sociais se uniram à promotoria para conseguirem um hospital que realizasse a operação, enfim concluída em Recife ${ }^{40}$.

Uma hipótese possível para esta discrepância entre a discussão da questáo em nível teórico e as práticas sociais pode ser o fato de que o princípio de laicidade do Estado bem como diversas outras diretrizes da Constituição da República encontram resistências disseminadas no corpo social. Estas resistências são de múltiplas ordens: moral, religiosa, corporativa etc. ${ }^{41}$

\footnotetext{
BRASIL. Supremo Tribunal Federal. Audiência Pública. Interrupção voluntária de gravidez. ADPF 442, 2018, p. 79

40 SUAREZ, J. As mulheres ainda lutam por direito a contracepçáo e ao aborto legal em comunidades pernambucanas, 2018.

${ }^{41}$ Este tema será objeto de trabalhos futuros.
} 
Ainda sobre os debates no âmbito da ADPF 442, é importante ressaltar que, embora as discussóes girem em torno da afirmação do direito à liberdade individual das mulheres sobre o controle da reprodução, é inegável que a descriminalização da prática implica e modula a política. Alçar este direito individual à categoria dos direitos fundamentais é imprescindível, pois diz respeito ao grau de democracia alcançado por determinada sociedade, o que demonstra que a questão trata de uma discussão que não concerne apenas ao direito individual das mulheres, mas que compóe a política e a democracia de maneira incontornável.

\section{REFERÊNCIAS}

ANDERSON, K. B. Marx nas margens: nacionalismo, etnia e sociedades não ocidentais. Tradução Allan M. Hillani, Pedro Davoglio. São Paulo: Boitempo, 2019.

BARSTOW, A. L. Chacina de feiticeiras: uma revisão histórica da caça às bruxas na Europa. Tradução Ismênia Tupy. Rio de Janeiro: José Olympio, 1995.

BRASIL. Decreto-lei no 2.848, de 7 de dezembro de 1940. Diário Oficial (da) República Federativa do Brasil, Poder Executivo, Brasília, DF, 31 dez. 1940. Seção 1, p. 23911.

BRASIL. Supremo Tribunal Federal. Audiência Pública. Interrupção voluntária de gravidez. ADPF 442, Brasília, DF, p. 1-623, 3 ago. 2018. Disponível em: <https://bit.ly/3gYxprM>. Acesso em: 20 maio 2020.

BRASIL. Supremo Tribunal Federal. Habeas-corpus no 124.306 da $1^{\text {a }}$ Turma. Inteiro Teor do Acórdáo, Brasília, DF, 9 ago. 2016.

CLASTRES. P. A sociedade contra o Estado: pesquisas de antropologia política. Tradução Theo Santiago. Sáo Paulo: Cosac Naify, 2003.

DELEUZE. G.; GUATTARI, F. Mil platôs: capitalismo e esquizofrenia. 2. ed. Tradução Peter Pal Pelbart, Janice Caiafa. São Paulo: Editora 34, 2012. vol. 5.

ENGELS, F. A origem da família, da propriedade privada e do Estado. Tradução Nelio Scheneider. São Paulo: Boitempo, 2019.

FEDERICI, S. Calibã e a bruxa: mulheres, corpo e acumulação primitiva. Tradução Coletivo Sycorax. São Paulo: Elefante, 2017.

KRAEMER, H.; SPRENGER, J. O martelo das feiticeiras. 28. ed. Tradução Paulo Fróes. Rio de Janeiro: Record, 2017.

LERNER. G. A criaçáo do patriarcado: história da opressão das mulheres pelos homens. Tradução Luiza Sellera. São Paulo: Cultrix, 2019.

MORGAN, L. H. La société archaïque. Traduit H. Jaouiche. Paris: Éditions Anthropos, 1971.

MURARO. R. M. Prefácio. In: KRAEMER, H.; SPRENGER, J. O martelo das feiticeiras. 28. ed. Tradução Paulo Fróes. Rio de Janeiro: Record, 2017. p. 9-21.

RIO DE JANEIRO. Defensoria Geral do Estado do Rio de Janeiro - DPGE. Entre a morte e a prisão: quem são as mulheres criminalizadas pela prática do aborto no Rio de Janeiro. Rio de Janeiro: DPGE, 2018. Disponível em: <https://bit.ly/36ZtTZk>. Acesso em: 20 maio 2020. 
SAHLINS, M. Cultura na prática. 2. ed. Tradução Vera Ribeiro. Rio de Janeiro: UFRJ, 2007.

SÃO PAULO. Núcleo de Promoção e Defesa dos Direitos da Mulher da Defensoria Pública do Estado de São Paulo - NUDEM. 30 habeas corpus: a vida e o processo de mulheres acusadas da prática de aborto em São Paulo. São Paulo: NUDEM, 2018. Disponível em: <https://www. defensoria.sp.def.br/dpesp/Repositorio/41/Documentos/30\%20habeas\%20corpus.pdf >. Acesso em: 20 maio 2020.

STRAUSS, L. Antropologia estrutural. Tradução Beatriz Perrone-Moisés. São Paulo: Ubu, 2017.

STRATHERN. M. O gênero da dádiva: problemas com as mulheres e problemas com a sociedade na Melanésia. Tradução André Villalobos. Campinas: Unicamp, 2006.

SUAREZ, J. As mulheres ainda lutam por direito a contracepção e ao aborto legal em comunidades pernambucanas. Pública: Agência de Jornalismo Investigativo, São Paulo, 21 ago. 2018. Disponível em: <https://bit.ly/30aVVzY>. Acesso em: 15 maio 2020. 